\title{
Properties of Concrete Containing New and Used Engines Oil
}

\author{
Mohammed Noori Hussein \\ Civil Engineering Department, Iraq University College
}

\begin{abstract}
Concrete structure is produced from cement, aggregate and water. The construction industries are turning out to be more challenging than any other time in recent memory. To be competitive, the field of engineering related to the industries need to a chance to be made. One of the areas that can be established is the used of material in the construction purposes. A specific scope of study on the engines oil in concrete mix is presented in this paper as to improve the knowledge in the field of construction technology. This paper presents a study on the fresh and hardened properties of concrete containing engines oil. Slumps, Compacting Factor Tests weredetermined for the fresh properties and Compressive Strength test of Concrete was determined for the hardened properties.
\end{abstract}

Keyword: Concrete, engines oil, Workability of concrete, Compressive Strength.

\section{Introduction}

Concrete is the material which most widely used in construction field over the world [1]. Nowadays, the utilization of concrete is amazingly high. From the statistic shown that, concrete is produced over six billions ton each year, and is the most generally utilized substance than other man-made material in the earth [2]. It is specific to different applications like reconstruction, renewal and construction. They include bridges, building structures, dams, basements, tunnels, streets, pavements, airports, and so onnormally, concrete consists of cement, sand, coarse aggregate and water.

Since concrete the most critical part in structural construction, its blend content should be in a form of good quality for structural purposes. Concrete is comprised of aggregate, cement and water. Through this blend of materials, three - quarter of the blend is administered by aggregate. The aggregate itself is classified as fine and course aggregate, and water is the assistant factor for the hydration process.

Water reducers are maybe the most broadly utilized admixtures in the concrete industry, their utilization in ready-mixed concrete being especially common. The main water-reducing mixes are lignosulphonates and hydro carboxylic acids and they work by connecting themselves to cement grains, imparting a negative charge which causes grains to disperse more adequately.

Water reducing admixtures will give side effects include air entrainment and retardation of set, though these are only slight at normal doses. Plasticizers are relatively cheap andform an economical means of improving concrete quality if used to increasing the strength when the water/cement ratio decreased. The effect of superplasticizers is short-lived only 30-45 minutes, hence theyare usually added to concrete just before placing. Care is necessary to avoid segregation but hardened properties, such as strength, shrinkage and creep do not appear to be adversely affected [3].Cement is a main material in concrete; however, in the process of producing cement, one important issue that has been carried out is air pollution. The production of one ton of Portland cement release approximately one ton of carbon dioxide and other greenhouse gases into the atmosphere [4]. In the broadest sense, the term cement can be described as a material with adhesive and cohesive properties which make it capable of bonding mineral fragments into a solid form. For construction purposes, the term ,cement ${ }^{\mathrm{ee}}$ is restricted to the bonding materials usedas a binding agent for sand, stone and other aggregates within the manufacture of mortar and concrete.

There are two types of cement; hydraulic cements and nonhydraulic cements. Hydraulic cements consist mainly of silicates and aluminates of lime, and can be arranged comprehensively as natural cements, Portland cements, and high alumina cements. Hydraulic cements set and harden by internal chemical reactions when mixed with water. Meanwhile, non-hydraulic cements will only harden gradually by ingestions of carbon dioxide from the air [5].

Aggregate was originally a composition of a concrete mix with the proportion to the cement content and also as an inert material dispersed throughout the cement paste largely for economic purposes. It is possible to take into account that aggregate is a building material connected into a cohesive whole by means of the cement paste, as a comparison similar to masonry work in building construction. Actually, the aggregate can assimilate heat, water, chemicals and also its physical properties will influence the performance of concrete.

Bond between aggregate and cement paste is an essential variable to create a strength of concrete hence because of this reason a fully understood about the material properties is very significant.

So, concrete industry has considered recycling industrial byproducts to be used as concrete additives in order to produce higher quality and more sustainable construction material.

Generally, there are two classes of additives; they are mineral additives and chemical additives. Mineral additives are fly ash, slag, silica fume, and different pozzolans. Then again, the chemical additives are such as accelerators, antifreeze admixtures, retarders, air-entrainment, water 


\section{International Journal of Science and Research (IJSR) \\ ISSN (Online): 2319-7064 \\ Index Copernicus Value (2013): 6.14 | Impact Factor (2014): 5.611}

reducers, superplasticizers and water repellents [6]. These additives are typically added to create different practices of concrete indicated by their applications.

\section{Materials}

\subsection{Cement}

Ordinary Portland cement is the most common type of cement in general utilize around the world because it is a basic component of concrete, mortar, stucco and most nonspecialty grout. The type of cement utilized in this study is imported Portland cement. Table1 shows the chemical composition of Portland cement.

Table 1: Chemical Composition of Ordinary Portland Cement

\begin{tabular}{|c|c|}
\hline Elements & Percentage by Mass (\%) \\
\hline $\mathrm{SiO} 2$ & 43.1 \\
\hline $\mathrm{Al} 2 \mathrm{O} 3$ & 5 \\
\hline $\mathrm{Fe} 203$ & 2.6 \\
\hline $\mathrm{CaO}$ & 46 \\
\hline $\mathrm{MgO}$ & 1.1 \\
\hline $\mathrm{TiO} 2$ & - \\
\hline $\mathrm{K} 2 \mathrm{O}$ & 0.5 \\
\hline $\mathrm{P} 2 \mathrm{O} 5$ & - \\
\hline $\mathrm{Na} 2 \mathrm{O}$ & 0.2 \\
\hline $\mathrm{SO} 3$ & - \\
\hline $\mathrm{LOI}$ & 1.3 \\
\hline Total & 100 \\
\hline
\end{tabular}

\subsection{Aggregates}

Locally available natural sand with $4.75 \mathrm{~mm}$ maximum size was used as fine aggregate. Crushed granite with $10 \mathrm{~mm}$ maximum size was used as coarse aggregate. Both fine aggregate and coarse aggregate conformed toIS: 383-1970 [7]. Table 2 gives the physical properties of the coarse aggregates and fine aggregates.

Table 2: Physical properties of coarse and fine aggregates

\begin{tabular}{|c|c|c|}
\hline Properties & $\begin{array}{c}\text { Coarse } \\
\text { aggregates }\end{array}$ & $\begin{array}{c}\text { Fine } \\
\text { aggregates }\end{array}$ \\
\hline Specific gravity & 2.66 & 2.65 \\
\hline Fineness modulus & 6.46 & 2.507 \\
\hline Bulk density $(\mathrm{kg} / \mathrm{m} 3)$ & 1545 & 1781 \\
\hline Water absorption (\%) & 0.90 & 0.98 \\
\hline
\end{tabular}

\subsection{Water}

Water used in mixing of concrete, including that free water on the aggregates, should be clean and free from impurities of oils, acids, alkalis, salts, organic material or other substances that may be deleterious to concrete.

\subsection{Engine Oil}

In this study, used engine oil is shown in Figure1 and new engine oil is shown in Figure 2. They are used as additive in the concrete. The used engine oil can be obtained from car workshop. The type of new engine oil used in this research is the LIQUI-MOLY 10W-30 engine oil as shown in figure 3 . The percentage of engine oil used in this research is 0.75 per cent from the weight of cement.

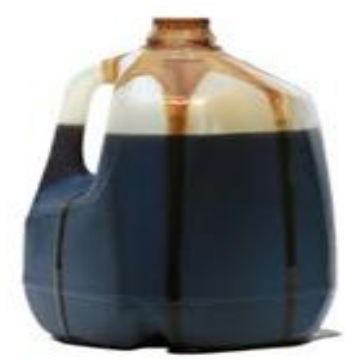

Figure 1: used engine oil
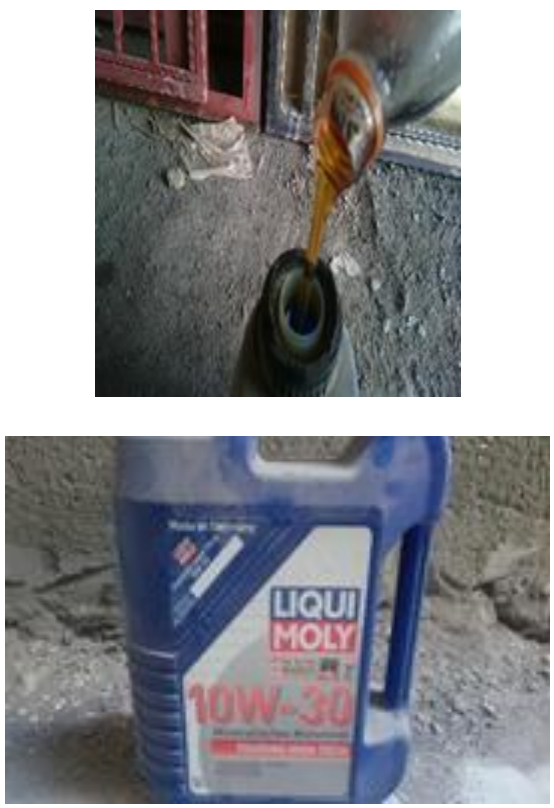

\section{Experimental Program}

In this research to determine the performance of concrete containing engine oil, fifty four concrete cubes samples were prepared and tested to obtain some of the basic engineering properties. These mixes were designed in such a way to achieve an ultimate compressive strength of $30 \mathrm{MPa}$. Based on DoE method, the proportions of the various ingredients used in the mixes are given in Table 3.

Table 3: Mix Proportions of concrete used in the study.

\begin{tabular}{|c|c|c|c|c|c|c|c|}
\hline \multirow{2}{*}{$\begin{array}{c}\text { Mix } \\
\text { No. }\end{array}$} & OPC & Water & Sand & $\begin{array}{c}\text { Crushed } \\
\text { granite of } \\
10 \mathrm{~mm}\end{array}$ & $\begin{array}{c}\text { Used } \\
\text { engine } \\
\text { Oil }\end{array}$ & $\begin{array}{c}\text { New } \\
\text { engine } \\
\text { Oil }\end{array}$ & $\begin{array}{c}\text { W/C } \\
\text { ratio }\end{array}$ \\
\hline 1 & 463 & 250 & 647 & 930 & - & - & 0.54 \\
\hline 2 & 463 & 250 & 647 & 930 & 3.47 & & 0.54 \\
\hline 3 & 463 & 250 & 647 & 930 & - & 3.47 & 0.54 \\
\hline 4 & 463 & 222 & 647 & 930 & - & - & 0.48 \\
\hline 5 & 463 & 222 & 647 & 930 & 3.47 & - & 0.48 \\
\hline 6 & 463 & 222 & 647 & 930 & - & 3.47 & 0.48 \\
\hline
\end{tabular}

\section{Mixing and Casting}

For these blend proportions, required amounts of materials were weighed. Cement, coarse and fine aggregates were blended dry independently. After adding water and engine oil all materials were combined to get the homogeneous blend. Subsequent to doing the tests for fresh properties, 


\section{International Journal of Science and Research (IJSR) \\ ISSN (Online): 2319-7064 \\ Index Copernicus Value (2013): 6.14 | Impact Factor (2014): 5.611}

final casting of the mixes was done immediately. After casting, test samples were left in the casting room for $24 \mathrm{~h}$ at a temperature of about $20 \_$C. The specimens were removed from mold after $24 \mathrm{~h}$ and were put into a water-curing tank until the time of the test or according to prerequisite of the test. The cubes of size $150 \mathrm{~mm}$ were cast for determination of compressive strength. The cubes were tested at the ages of 7,28 and 56 days to study the development of compressive strength. The details of samples are shown in Table 4.

Table 4: Types of Concrete Mixes and Test Ages

\begin{tabular}{|c|c|c|c|}
\hline \multirow{2}{*}{ Concrete Mix } & \multicolumn{3}{|c|}{ Test Age (Days) } \\
\cline { 2 - 4 } & 7 & 28 & 56 \\
\hline Concrete without engine oil(Control) & 3 & 3 & 3 \\
\hline Concrete with 0.75\% new engine oil & 3 & 3 & 3 \\
\hline Concrete with 0.75\% used engine oil & 3 & 3 & 3 \\
\hline $\begin{array}{c}\text { Concrete without engine oil+ } \\
\text { reduce W/C to 0.48 }\end{array}$ & 3 & 3 & 3 \\
\hline $\begin{array}{c}\text { Concrete with 0.75\% new engine oil+ } \\
\text { reduce W/C to 0.48 }\end{array}$ & 3 & 3 & 3 \\
\hline $\begin{array}{c}\text { Concrete with 0.75\% used engine oil+ } \\
\text { reduce W/C to 0.48 }\end{array}$ & 3 & 3 & 3 \\
\hline
\end{tabular}

\section{Testing}

\subsection{Fresh properties}

The test of fresh concrete is related to the workability test. Generally, there are four types of tests that are being used widely to measure the workability of concrete. The four types of tests are slump test, compacting factor test, vebe test and flow test. In this research, the workability tests chosen are the slump test and the compacting factor.

\subsubsection{Slump Test}

The method of slump test is prescribed by BS1881: Part 102: 1983 [8]. The mould for the slump test is a frustum of cone, $300 \mathrm{~mm}$ high. Table 5 shows the description of workability and magnitude of slump.

Table 5: Description of Workability and Magnitude of Slump [9]

\begin{tabular}{|c|c|}
\hline Description of workability & Slump Value (mm) \\
\hline No slump & 0 \\
\hline Very low & $5-10$ \\
\hline Low & $15-30$ \\
\hline Medium & $35-75$ \\
\hline High & $80-155$ \\
\hline Very high & 160 to collapse \\
\hline
\end{tabular}

\subsubsection{Compacting Factor Test}

The workability of concrete has been defined as the amount of work required to place the concrete and compact it thoroughly without segregation. It is simpler to apply a standard amount of work to the concrete and to measure its degree of compaction.

The degree of compaction is defined as compacting factor which is measured by the density ratio, for example, the ratio of density actually achieved in the test to the density of the same concrete fully compacted. Table 6 shows the value of the compacting factor for different workability.
Table 6: Description of Workability and Compacting Factor [9]

\begin{tabular}{|c|c|c|}
\hline $\begin{array}{c}\text { Description of } \\
\text { Workability }\end{array}$ & $\begin{array}{c}\text { Compacting } \\
\text { Factor }\end{array}$ & $\begin{array}{c}\text { Corresponding Slump } \\
\text { (mm) }\end{array}$ \\
\hline Very low & 0.78 & $0-25$ \\
\hline Low & 0.85 & $25-50$ \\
\hline Medium & 0.92 & $50-100$ \\
\hline Medium & 0.95 & $100-175$ \\
\hline
\end{tabular}

\subsection{Cube Compressive Strength test}

For determining the compressive strength of the concrete, the method used is in accordance with BS 1881: Part 116: 1983[10]. The load on the cube is applied at a constant rate until the specimen crushes at the maximum load applied.

\section{Results and Discussion}

\subsection{Fresh Concrete Properties}

The results of various fresh properties tested by slump test and Compacting FactorTest, for various mix compositions are given in Table 7 and table 8 respectively. The slump test results show that the concrete with $0.75 \%$ used engine oil have the highest slump value followed by Concrete with $0.75 \%$ used engine oil and control sample. Concrete added with new engine oil also has workability higher than control sample. The result achieved from the slump test indicates that the use of engine oil will increase the workability of concrete. In the concrete, engine oil will act as lubricant that makes the concrete more workable. concrete with used engine oil and new engine oil have lower compacting factor compared to control sample and concrete with $0.48 \mathrm{~W} / \mathrm{C}$ ratio.

Table 7: Result of Slump Test

\begin{tabular}{|c|c|}
\hline Concrete Mix. & $\begin{array}{c}\text { Slump } \\
\text { result(mm) }\end{array}$ \\
\hline Control & 68 \\
\hline Concrete with $0.75 \%$ new engine oil & 73 \\
\hline Concrete with $0.75 \%$ used engine oil & 77 \\
\hline Concrete without engine oil+ reduce W/C to 0.48 & 59 \\
\hline $\begin{array}{c}\text { Concrete with } 0.75 \% \text { new engine oil+ reduce W/C } \\
\text { to 0.48 }\end{array}$ & 63 \\
\hline $\begin{array}{c}\text { Concrete with 0.75 \% used engine oil+ reduce } \\
\text { W/C to } 0.48\end{array}$ & 67 \\
\hline
\end{tabular}

Table 8: Result of Compacting Factor Test

\begin{tabular}{|c|c|}
\hline Concrete Mix. & $\begin{array}{c}\text { Compacting } \\
\text { factor \% }\end{array}$ \\
\hline Control & 97 \\
\hline Concrete with 0.75\% new engine oil & 91 \\
\hline Concrete with 0.75\% used engine oil & 90 \\
\hline Concrete without engine oil+ reduce W/C to 0.48 & 99 \\
\hline $\begin{array}{c}\text { Concrete with 0.75\% new engine oil+ } \\
\text { reduce W/C to 0.48 }\end{array}$ & 88 \\
\hline $\begin{array}{c}\text { Concrete with } 0.75 \% \text { used engine oil+ } \\
\text { reduce W/C to 0.48 }\end{array}$ & 89 \\
\hline
\end{tabular}

\subsection{Compressive Strength of Concrete}

At any stage of hydration, the hardened cement paste consists of crystallized hydrates (C-S-H gel), crystals of calcium hydroxide, some minor components, unhydrated cement and water-filled spaces. The crystallized hydrates are

\section{Volume 4 Issue 12, December 2015}




\section{International Journal of Science and Research (IJSR) \\ ISSN (Online): 2319-7064 \\ Index Copernicus Value (2013): 6.14 | Impact Factor (2014): 5.611}

made up of small (submicroscopic) interlocking crystals. The crystallized hydrates in the cement paste are to bind the aggregates together and for strength purpose. Water/cement ratio significantly affects the microstructure of the hardened cement paste. At low water/cement ratio, the hydro-silicates are of a soft plate-like nature with little fibers in the pores whilst at high water/cement ratio, there are an increase in porosity and an increase in fibers in the pores.

The control sample shows a fairly high compressive strength as shown in figure 4. The average compressive strength of the control sample at the age of 28 days is $31.1 \mathrm{MPa}$ which is greater than the design strength of $30 \mathrm{MPa}$. This high strength improvement rather because of good quality control within the made up of the concrete. The average compressive strength of the concrete added with $0.75 \%$ new engine oil is $27.3 \mathrm{MPa}$ in 28 days as shown in figure 5 , and does not reach the design strength of $30 \mathrm{MPa}$. The results obtained shows that the usage of new engine oil in the concrete will affect the bonding of the aggregate and the $\mathrm{C}$ $\mathrm{S}-\mathrm{H}$ gel thus, decrease the compressive strength of the concrete. While the average compressive strength of concrete with $0.75 \%$ used engine oil gives $29.7 \mathrm{MPa}$ in 28 days as shown in figure 6 , which is more than compressive strength of the concrete with new engine oil and that's because the viscosity of new engine oil is higher than the viscosity of used engine oil, but the use of both new and used engine oil gives lower compressive strength compared with the control sample and that because engine oil will effect on the bonding of the aggregate in the concrete.

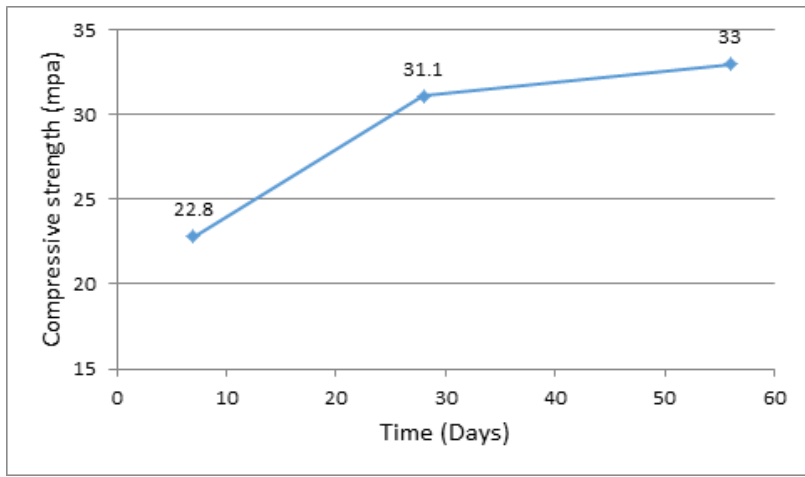

Figure 4: Average Compressive Strength with Age for control sample

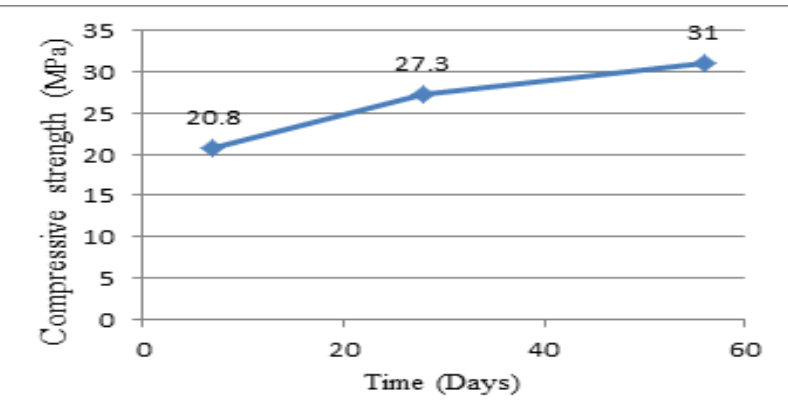

Figure 5: Average Compressive Strength with Age for concrete with new engine oil

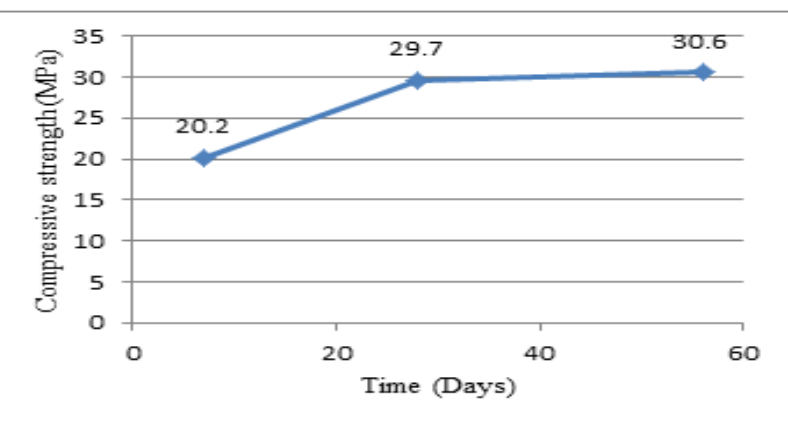

Figure 6: Average Compressive Strength with Age for concrete with used engine oil

Based on figure7, the strength of concrete without engine oil with 0.48 water-cement ratio and concrete added $0.75 \%$ new and used engine oil achieved more than control strength at 28 days. The average compressive strength of the control is only $31.1 \mathrm{MPa}$ while the average compressive strength of the three types of concretegives $33.2 \mathrm{MPa}, 32 \mathrm{MPa}$ and $32.8 \mathrm{MPa}$ respectively. Figure 8 shows Schematic Diagram of Cement Paste of Concrete with engine oil during the hydration process

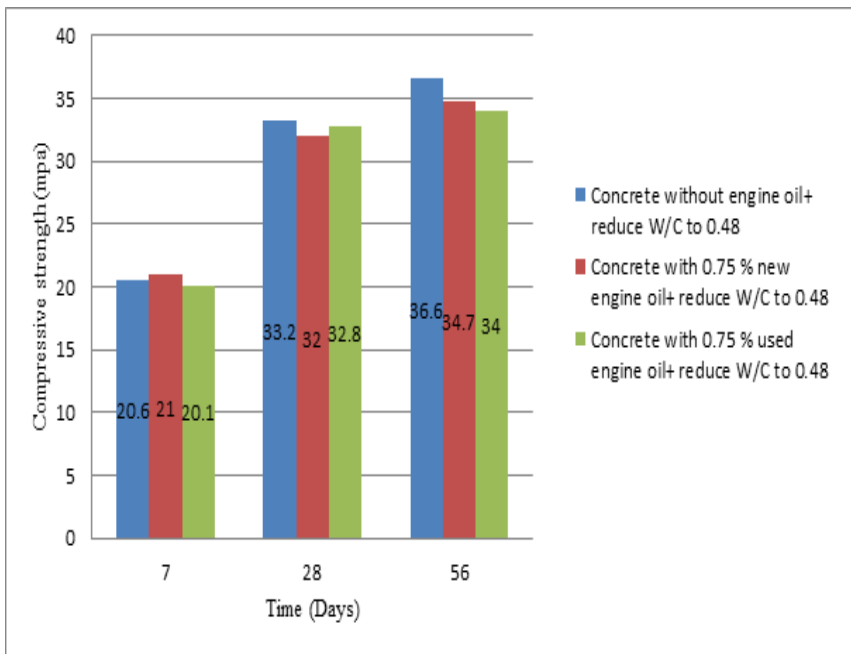

Figure7: Average Compressive Strength with Age

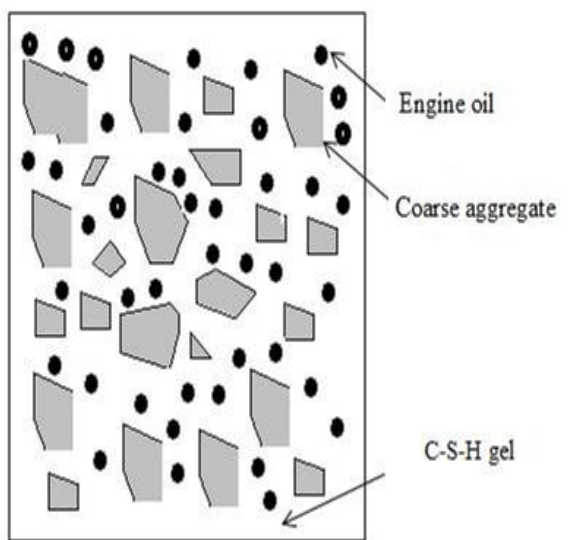

Figure 8: Schematic Diagram of Cement Paste of Concrete with engine oil

\section{Conclusion}

1) Concrete with used engine oil has the highest workability followed by concrete with new engine oil. Concrete 


\section{International Journal of Science and Research (IJSR) \\ ISSN (Online): 2319-7064}

Index Copernicus Value (2013): 6.14 | Impact Factor (2014): 5.611

added with new engine oil also has workability higher than control sample. The result achieved from the slump test indicates that the use of engine oil will increase the workability of concrete. In the concrete, engine oil will act as lubricant that makes the concrete more workable. However, concrete with used engine oil and concrete with new engine oil have lower compacting factor compared to control sample and concrete

2) Concrete without engine oil has the highest final compressive strength. Concrete with used engine oil and concrete with new engine oil have lower compressive strength compared to control sample because the use of engine oil in the concrete will reduce the bonding between aggregate and C-S-H gel. The result obtained in this research also shows that concrete with used engine oil has better compressive strength compared to concrete with new engine oil because the viscosity of used engine oil is lower than the new engine oil. However the concrete with $0.48 \mathrm{~W} / \mathrm{C}$ ratios has compressive strength higher than the control sample because the reduction of $\mathrm{W} / \mathrm{C}$ ratio will decrease the amount of voids in the concrete and that gives higher compressive strength.

\section{References}

[1] Lomborg B. (2001), The Skeptical Environmentalist: Measuring the Real State of the World (2nd edition), United Stated of America, The press Syndicate of The University of Cambridge.

[2] Oss H.G. (2007), Patent No. OF-2007-1152, Retrieved on $16 \quad$ January 2008. http://minerals.usgs.gov/minerals/pubs/commodity/cem ent/cemenmes07.pdf.

[3] Ho, D.W.S, Mak, S.L. and Sirivivatnanon (26-27 August 1991). "Performance of Concrete Incorporating Chemical and Mineral Admixtures". $16^{\text {th }}$ Conference on Our World In Concrete \& Structures.

[4] Naik T.R. (2005), Sustainability of Cement and Concrete Industries, Presented and Published at the Global Construction: Ultimate Cocnrete Opportunities, July 2005, Dundee, Scotland.

[5] Dhir R.K., Hewlett P.C. \& Jones M.R. (1999), Creating with Concrete (1st edition), Heron Quay, London, Thomas Telford Publishing.

[6] Lyons, A (2004). "Materials for Architects \& Builders". United Kingdom : Butterworth-Heinemann Publishers.

[7] IS: 383-1970. Specifications for Coarse and Fine aggregates from Natural sources for Concrete. Bureau of Indian Standards, New Delhi, India

[8] BS1881: Part 102: 1983: "Testing Concrete : Method for Determination of Slump". London: British Standard Institution

[9] BS1881: Part 103: 1983: "Testing Concrete : Method of Determination of Compacting Factor". London: British Standard Institution

[10] British Standard Institution, BS 1881: Part 116 (1983). "Methods for Determination of Compressive Strength of Concrete Cube". 